Research Article

\title{
Spectrum and Prevalence of Thyroid Diseases at a Tertiary Referral Hospital in Mogadishu, Somalia: A Retrospective Study of 976 Cases
}

\author{
Mohamed A. Hassan-Kadle ${ }^{D},{ }^{1}$ Abdulkamil Abdullahi Adani ${ }^{D},{ }^{2}$ Hasan Huseyin Eker (D), ${ }^{3}$ \\ Esra Keles $\left(\mathbb{D},{ }^{4}\right.$ Marian Muse Osman $\left(\mathbb{D},{ }^{5}\right.$ Hussein Mahdi Ahmed (D), ${ }^{2}$ \\ and Şeyma Görçin Karaketir iD ${ }^{6}$ \\ ${ }^{1}$ Som Gastro Clinic, Center for Digestive and Liver Disease, College of Medicine \& Health Science, Abrar University, \\ Mogadishu, Somalia \\ ${ }^{2}$ Department of Internal Medicine, University of Health Sciences Turkey, \\ Mogadishu Somalia-Turkey Recep Tayyip Erdoğan Training and Research Hospital, Mogadishu, Somalia \\ ${ }^{3}$ Department of Public Health, University of Health Sciences Turkey, Hamidiye Faculty of Medicine, Istanbul 34668, Turkey \\ ${ }^{4}$ Department of Gynecologic Oncology, University of Health Sciences Turkey, Zeynep Kamil Training and Research Hospital, \\ Istanbul 34668, Turkey \\ ${ }^{5}$ Department of Public Health, University of Health Sciences Turkey, \\ Mogadishu Somalia-Turkey Recep Tayyip Erdoğan Training and Research Hospital, Mogadishu, Somalia \\ ${ }^{6}$ Occupational Health Training Programme, Department of Public Health, İstanbul University, İstanbul School of Medicine, \\ Istanbul, Turkey
}

Correspondence should be addressed to Mohamed A. Hassan-Kadle; kadlesom@gmail.com

Received 4 August 2021; Accepted 7 December 2021; Published 26 December 2021

Academic Editor: Alexander Schreiber

Copyright (c) 2021 Mohamed A. Hassan-Kadle et al. This is an open access article distributed under the Creative Commons Attribution License, which permits unrestricted use, distribution, and reproduction in any medium, provided the original work is properly cited.

Background. Thyroid disorder is one of the most common noncommunicable diseases worldwide and neglected public health issues in Somalia. The aim of the study thus was to investigate the thyroid disorders in patients attending to the largest tertiary referral hospital in Somalia. Methods. This retrospective study was conducted on patients admitted to the internal department of Somalia Mogadishu-Turkey Education and Research Hospital, Somali, between January 2017 and December 2019. Patients who were tested for thyroid function tests and had complete data were included. Patients with incomplete data and currently treated for any thyroid disorder were excluded from the study. Abstracted data including patients' sociodemographic characteristics, thyroid function tests, and histopathological findings were retrieved from the hospital database system. Results. A total of 976 patients with thyroid disorders were enrolled, of whom $66.6 \%(n=650)$ were female and $33.4 \%(n=326)$ were male. The mean age of the patients was $47 \pm 18.5$ years. The majority of the patients were reported in the 31-50 (35.9\%) age range. The most reported thyroid function disorders were $58.8 \%$ euthyroid sick syndrome followed by $15.4 \%$ hypothyroidism, $12.5 \%$ subclinical hypothyroidism, 7.6\% hyperthyroidism, and 5.7\% subclinical hyperthyroidism. The distribution of comorbidity indicated that $13.4 \%$ had diabetes mellitus, $10.4 \%$ had HIV , $4.9 \%$ had malaria, and $4.5 \%$ had HIV and malaria coinfection. Thyroid malignancies were detached in 22 (2.2\%) patients including eleven papillary thyroid cancer, nine patients had follicular thyroid cancer, and two patients had differentiated thyroid cancer. Conclusions. Euthyroid sick syndrome was the most common type of thyroid disease in our setup. Hypothyroidism is the second most common, followed by subclinical hypothyroidism. Papillary thyroid cancer was the predominant histology among thyroid malignancies, followed by follicular thyroid cancer. This study revealed that thyroid diseases emerge as an important endocrine disorder encountered in Somali, necessitating a major public health response. 


\section{Introduction}

Thyroid diseases are one of the most important public health problems worldwide ranking second in endocrine diseases after diabetes mellitus including Africa [1, 2]. In Africa, they were rare particularly in the early 1960s, although the 1970 s saw an increase in reported cases of thyroid diseases in Africans, and iodine deficiency was also noted to be the most common cause of thyroid disorders $[3,4]$.

Iodine is a trace element in the synthesis of thyroid hormones, and the thyroid gland secretes two metabolic hormones, thyroxine (T4) and triiodothyronine (T3), regulating metabolic rate, growth, and development $[5,6]$. These hormones produced by the thyroid gland are imbalanced in the regulation which can cause many disorders including hypothyroidism, subclinical hypothyroidism, hyperthyroidism, subclinical hyperthyroidism, and secondary hypothyroidism [6,7].

Globally, the main micronutrients including iodine are a public health problem affecting all segments of the population. Sub-Saharan Africa had been classified as an area of moderate-to-severe iodine deficiency for a long time. Therefore, the thyroid disease burden in Africa represents above $25 \%$ of the worldwide [4]. Somalia is a coastal country that has the second longest coastline in Africa. It is also one of the African countries where groundwater is the primary source of dietary iodine. But the deficiency of micronutrients including iodine among the Somalis population is due to the limited access to iodized salt and high existence of cultural beliefs and barriers that delay the consumption or inadequate intake of these micronutrients including iodine [8-10].

This study was to document all types of thyroid diseases seen in the largest referral hospital in the country to be the baseline data for future research studies about this disease; to the best of our knowledge, this is the first study to be reported from Somalia before and after the Civil War.

\section{Materials and Methods}

We retrospectively analyzed the records of patients with thyroid disorder who were admitted to the internal medicine department of Somalia Mogadishu-Turkey Recep Tayyip Erdogan Training and Research Hospital, Somalia, between January 1, 2017, and December 31, 2019. Our hospital is the largest multidisciplinary tertiary referral healthcare center of the region. This study was approved by the research ethics committee of Somali Mogadishu-Turkey Recep Tayyip Erdogan Training and Research Hospital (13.05.2020MSTH/3790). The database management was in accordance with privacy legislation, and the presented study was in accordance with the ethical principle of the Declaration of Helsinki.

Data were obtained through hospital's electronic database system for the records of patients diagnosed with thyroid disease in our hospital. Patients diagnosed with thyroid disease and with complete data were included in the study. Patients with incomplete data and currently treated for any thyroid disorder were excluded from the study.
Abstracted data included patients' demographic and clinical characteristics (age, gender, and comorbidities), histopathological findings, and the results of thyroid function tests consisting of thyroid-stimulating hormone (TSH), free thyroxine (FT4), and free triiodothyronine (FT3). Histopathological findings were classified as benign and malignant. Papillary thyroid cancer, follicular thyroid cancer, and differentiated thyroid cancer were defined as malignant pathology.

The patients were categorized into 5 groups as subclinical hypothyroidism, hypothyroidism, euthyroid sick syndrome, subclinical hyperthyroidism, and hyperthyroidism, and their definitions were defined according to the American Association of Clinical Endocrinologists (AACE) in association with American Thyroid Association (ATA) guidelines 2013 [11]. The normal range for thyroid function assays in our institution is TSH $0.35-5.10 \mu \mathrm{IU} / \mathrm{mL}$, FT4 $0.60-1.20 \mathrm{ng} / \mathrm{mL}$, and FT3 $1.80-4.20 \mathrm{pg} / \mathrm{mL}$. Hypothyroidism was defined to FT $4<0.60 \mathrm{ng} / \mathrm{mL}$ and $\mathrm{TSH}>5.1 \mu \mathrm{IU} / \mathrm{mL}$, and subclinical hypothyroidism was defined as normal free hormone levels and a TSH $>5.1 \mu \mathrm{IU} / \mathrm{mL}$. Hyperthyroidism was defined as FT4 $>1.20 \mathrm{ng} / \mathrm{mL}$ and $\mathrm{TSH}<0.35 \mu \mathrm{IU} / \mathrm{mL}$, and subclinical hyperthyroidism was defined as normal free hormone levels and $\mathrm{TSH}<0.35 \mu \mathrm{IU} / \mathrm{mL}$. Euthyroid sick syndrome was defined as $\mathrm{FT} 3<1.80 \mathrm{pg} / \mathrm{mL}, \quad \mathrm{TSH}<5.10 \mu \mathrm{IU} / \mathrm{mL}$, and FT $4<0.60 \mathrm{ng} / \mathrm{mL}$. Thyroid function tests were measured by a Roche e411 Immunoassay Analyzer (Roche Diagnostics Corporation, Indianapolis, IN).

All statistical analyses were performed using SPSS software version 23. Descriptive analyses were presented using means, standard deviations, and median values. The proportions were presented using tables of frequencies and percentages. The chi-square test or Fisher's exact test, where appropriate, was used to compare these proportions in different groups using the Bonferroni correction to adjust for multiple comparisons. The variables were investigated using visual (histograms) and analytical methods (Kolmogorov-Smirnov) to determine whether or not they are normally distributed. Kruskal-Wallis and Mann-Whitney $U$ tests were used to compare the parameters between the groups. A $p$ value of less than 0.05 was considered statistically significant.

\section{Results}

A total of 976 patients with thyroid disorders were enrolled in this study, of whom $66.6 \%(n=650)$ were female and $33.4 \%(n=326)$ were male. The mean age of the patients was $47 \pm 18.5$; most of the patients were in the age range of $31-50$ (35.9\%; $n=350)$. Distribution of the patients by thyroid function disorders showed that the majority of patients have euthyroid sick syndrome $(58.8 \% ; n=571)$, while $15.4 \%$ $(n=150)$ of the patients were diagnosed with hypothyroidism, $12.5 \%(n=121)$ were diagnosed with subclinical hypothyroidism, $7.6 \%(n=74)$ were diagnosed with hyperthyroidism, and $5.7 \%(n=55)$ were diagnosed with subclinical hyperthyroidism. When the distribution of comorbidity among 972 patients was examined, it was observed that $13.4 \%$ had diabetes mellitus (DM), $10.4 \%$ had 
HIV, $4.9 \%$ had malaria, and $4.5 \%$ had HIV and malaria coinfection. The characteristics of the study population are presented in Table 1. Thyroid malignancies were identified in $22(2.2 \%)$ patients. Half of these patients had papillary thyroid cancer $(n=11)$. Nine patients had follicular thyroid cancer, and two patients had differentiated thyroid cancer. Additionally, the distribution of thyroid carcinoma subtypes can be seen in Figure 1 .

There was a statistically significant difference between thyroid function disorders and gender $(p \leq 0.001)$. The euthyroid sick syndrome had been defined in $68.8 \%$ of males, while this was $53.8 \%$ in females. However, subclinical hyperthyroidism (6.3\%), hyperthyroidism (9.6\%), hypothyroidism (16.4\%), and subclinical hypothyroidism (13.9\%) were more common in females than in males. Age distribution in thyroid dysfunctions showed a statistically significant difference $(p \leq 0.001)$. The mean age of the hyperthyroidism group was $38 \pm 14.6$ years, the euthyroid sick syndrome group was $49 \pm 19.6$ years, and subclinical hypothyroidism was $48 \pm 18.8$ years. Of the 22 patients with thyroid cancer, 11 patients were in the euthyroid sick syndrome group, five patients were diagnosed with hypothyroidism, five patients were diagnosed with subclinical hypothyroidism, and one patient was diagnosed with subclinical hyperthyroidism. Euthyroid sick syndrome constitutes the majority of patients in all comorbidity groups, while $15 \%$ of patients with malaria were diagnosed with hypothyroidism, $15 \%$ subclinical hypothyroidism, $6 \%$ subclinical hyperthyroidism, and $1 \%$ hyperthyroidism; this rate was $8.5 \%, 21.5 \%, 6.4 \%$, and $0 \%$ in HIV, respectively. Additionally, it was $11.5 \%, 12.3 \%, 11.5 \%$, and $7 \%$ in DM, respectively. The distribution of the patients by thyroid function disorders is shown in Table 2.

The distribution of thyroid function disorders according to benign histopathology was as follows: euthyroid sick syndrome $59 \%$, hypothyroidism $15 \%$, subclinical hypothyroidism $12 \%$, hyperthyroidism $8 \%$, and subclinical hyperthyroidism $6 \%$. The distribution of malignant thyroid cancer subtypes can be seen in Figure 1.

The distribution of thyroid cancers by comorbidities indicated that all patients had malaria, 16 patients had HIV, and one patient had DM. In addition, all patients with HIV also had a diagnosis of malaria. All 11 patients with papillary thyroid cancer had malaria, 9 had HIV, and one person had DM. When the distribution of follicular thyroid cancer $(n=9)$ by comorbidity was examined, it was seen that all of them had malaria, and 6 had malaria and HIV coinfection. Among the two patients diagnosed with differentiated thyroid cancer, one had malaria infection, and the other had both malaria and HIV coinfection. The distribution of thyroid cancers by comorbidities is presented in Figure 2.

The age distribution of thyroid patients by gender revealed that the most common age group in males and females was between 31 and 50 , with a rate of $35 \%$. The age group distribution showed a similar distribution between genders. The most common age groups were $51-70,18-30$, $71-90$, and 91 and above, respectively. The age distribution of the patients by gender is presented in Figure 3.
TABLE 1: Baseline characteristics of the patients $(n=971)$, January 2017-December 2019, Somalia.

\begin{tabular}{lc}
\hline & $n(\%)$ \\
\hline Gender & \\
Female & $650(66.6)$ \\
Male & $326(33.4)$ \\
Age (years, mean \pm SD) & $47 \pm 18.5$ \\
Age groups & \\
$18-30$ & $236(24.2)$ \\
$31-50$ & $350(35.9)$ \\
$51-70$ & $269(27.6)$ \\
$71-90$ & $116(11.9)$ \\
$\geq 91$ & $5(0.5)$ \\
Diagnosis & \\
Subclinical hyperthyroidism & $55(5.7)$ \\
Hyperthyroidism & $74(7.6)$ \\
Euthyroid sick syndrome & $571(58.8)$ \\
Hypothyroidism & $150(15.4)$ \\
Subclinical hypothyroidism & $121(12.5)$ \\
Comorbidities & \\
DM & $131(13.4)$ \\
HIV & $101(10.4)$ \\
Malaria & $48(4.9)$ \\
HIV and malaria & $44(4.5)$ \\
Type & \\
Benign & $954(97.8)$ \\
Malignant & $22(2.2)$ \\
Differentiated & $2(0.2)$ \\
Follicular & $9(0.9)$ \\
Papillary & $11(1.1)$ \\
\hline
\end{tabular}

\section{Discussion}

Thyroid disorder is a neglected major public health issue and the most common noncommunicable disease in developing countries [12]. Thyroid disease is one of the most common endocrine disorders worldwide ranking second in endocrine diseases after diabetes mellitus including Africa $[1,2]$. This is the first study to examine the course of thyroid diseases in Somalia before and after the Civil War. This present study showed that the female population was common than the male population, and similar studies showed that the female population was predominant in Ethiopia, Kenya, Ghana, Nigeria, and Yemen and in sub-Saharan countries and the Middle East [4, 7, 13-17]. Thyroid disorder is the most common disease of the endocrine system which is increasing predominantly among females in the world [18]. Our study also showed that the mean age is 47 years, in line with studies in Ghana (43 years), Nigeria (42 years), Nepal (39 years), and Yemen (37 years) $[4,6,19]$, and the most age group of our study was 31-50, while in Nepal, it was $31-45$ years [6].

In the present study, we found that the most common type of thyroid disorder is euthyroid sick syndrome (58.8\%). Euthyroid sick syndrome is characterized by the changes in the thyroid hormonal level in acute and chronic illness due to nonthyroid illness caused by the inhibition of an enzyme called 5-deiodinase by various pathogeneses which catalyzes $\mathrm{T} 4$ to T3 conversion. While low T3 levels and high T4 and rT3 levels were seen in acute changes, low T3, T4, and TSH levels were seen in chronic changes. Therefore, euthyroid sick syndrome is seen mostly in severe critical illness followed by 


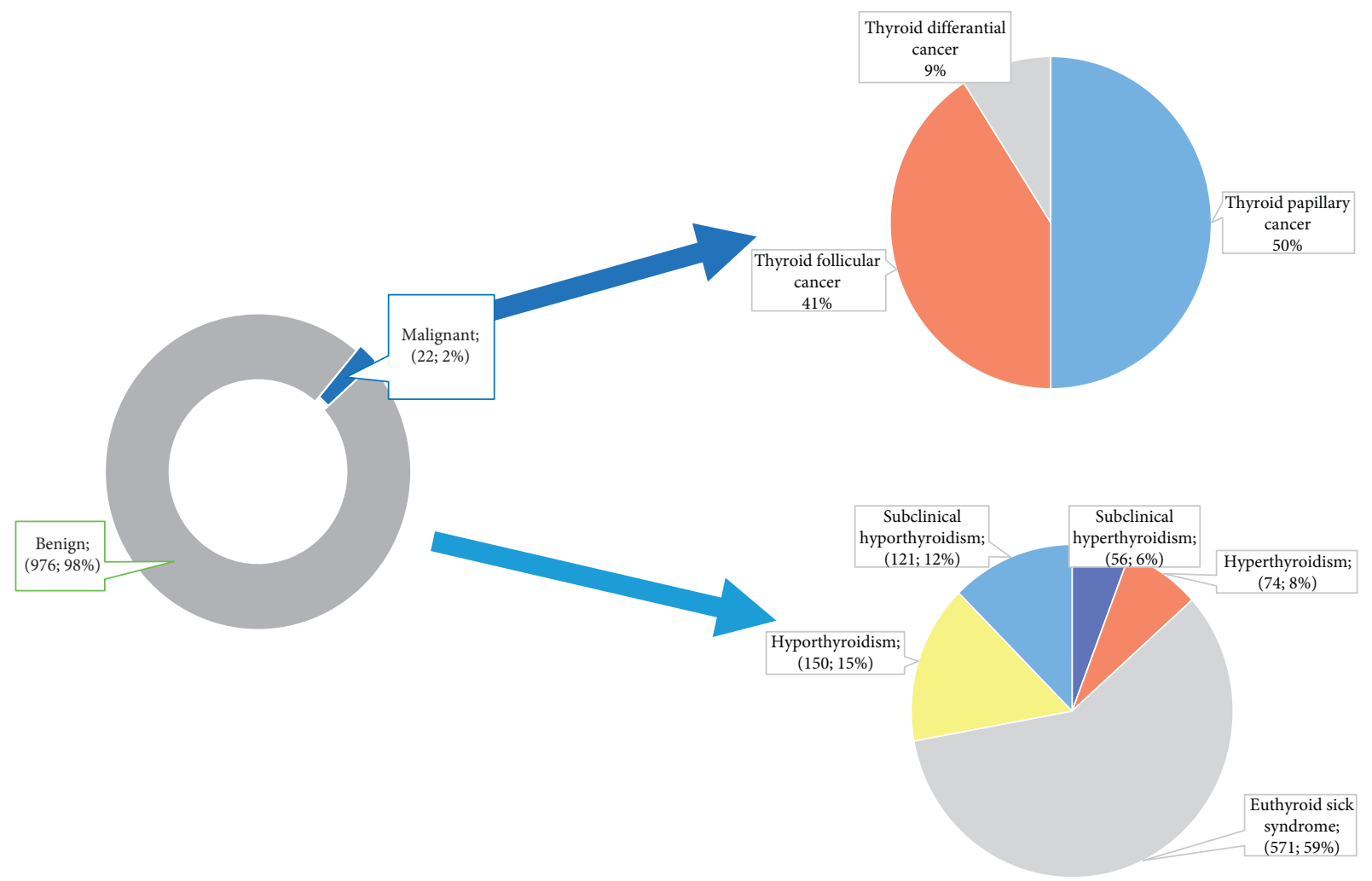

FiguRE 1: Distribution of thyroid disease cases $(n=976)$ by histopathological results and thyroid function disorders' subgroups, January 2017-December 2019, Somalia.

TABLE 2: Baseline characteristics of the patients according to thyroid function disorders $(n=971)$, January 2017-December 2019, Somalia.

\begin{tabular}{|c|c|c|c|c|c|}
\hline & $\begin{array}{c}\text { Subclinical } \\
\text { hyperthyroidism }(n=55)\end{array}$ & $\begin{array}{l}\text { Hyperthyroidism } \\
(n=74)\end{array}$ & $\begin{array}{l}\text { Euthyroid } \\
\text { sick } \\
\text { syndrome } \\
(n=571)\end{array}$ & $\begin{array}{l}\text { Hypothyroidism } \\
\quad(n=150)\end{array}$ & $\begin{array}{c}\text { Subclinical } \\
\text { hypothyroidism }(n=121)\end{array}$ \\
\hline \multicolumn{6}{|l|}{ Gender $(n, \%)^{*}$} \\
\hline Female & $41(6.3)$ & $62(9.6)$ & $348(53.8)$ & $106(16.4)$ & $90(13.9)$ \\
\hline Male & $14(4.3)$ & $12(3.7)$ & $223(68.8)$ & $44(13.6)$ & $31(9.6)$ \\
\hline $\begin{array}{l}\text { Age }(\text { mean } \pm S D) \text {, } \\
\text { years* }\end{array}$ & $44 \pm 16.1$ & $38 \pm 14.6$ & $49 \pm 19.6$ & $45 \pm 15.3$ & $48 \pm 18.8$ \\
\hline \multicolumn{6}{|l|}{ Age groups $(n, \%)$} \\
\hline $18-30$ & $11(4.7)$ & $28(12)$ & $140(59.8)$ & $30(12.8)$ & $25(10.7)$ \\
\hline $31-50$ & $29(8.4)$ & $32(9.2)$ & $166(47.8)$ & $73(21)$ & $47(13.5)$ \\
\hline $51-70$ & $11(4.1)$ & $11(4.1)$ & $176(65.4)$ & $36(13.4)$ & $35(13)$ \\
\hline $71-90$ & $4(3.4)$ & $3(2.6)$ & $86(74.1)$ & $11(9.5)$ & $12(10.3)$ \\
\hline$\geq 91$ & $0(0.0)$ & $0(0.0)$ & $3(60)$ & $0(0.0)$ & $2(40)$ \\
\hline \multicolumn{6}{|c|}{ Histopathological results $(n, \%)$} \\
\hline Thyroid cancer & $1(4.5)$ & $0(0.0)$ & $11(50)$ & $5(22.7)$ & $5(22.7)$ \\
\hline \multicolumn{6}{|c|}{ Comorbidities $(n, \%)$} \\
\hline Malaria & $6(6.0)$ & $1(1.0)$ & $63(63)$ & 15 (15) & $15(15)$ \\
\hline HIV & $3(6.4)$ & 0 & $30(63.8)$ & $4(8.5)$ & $10(21.5)$ \\
\hline Malaria + HIV & $3(7)$ & 0 & $27(62.8)$ & $3(7)$ & $10(23.5)$ \\
\hline $\begin{array}{l}\text { Diabetes } \\
\text { mellitus }\end{array}$ & $15(11.5)$ & $7(5.4)$ & $77(59.2)$ & $15(11.5)$ & $16(12.3)$ \\
\hline
\end{tabular}

${ }^{*} p \leq 0.001$.

major surgeries and inpatient or intensive care settings $[20,21]$. A possible explanation for the majority of patients with euthyroid syndrome in our study is that our hospital is the largest multidisciplinary tertiary hospital in the region to which patients with chronic diseases were referred.
The second most common thyroid disease was primary hypothyroidism (15.4\%), followed by subclinical hypothyroidism (12.5\%), which was similar but more than the percentage found in a Nepal study that showed hypothyroidism was $29.6 \%$ and subclinical hypothyroidism was 


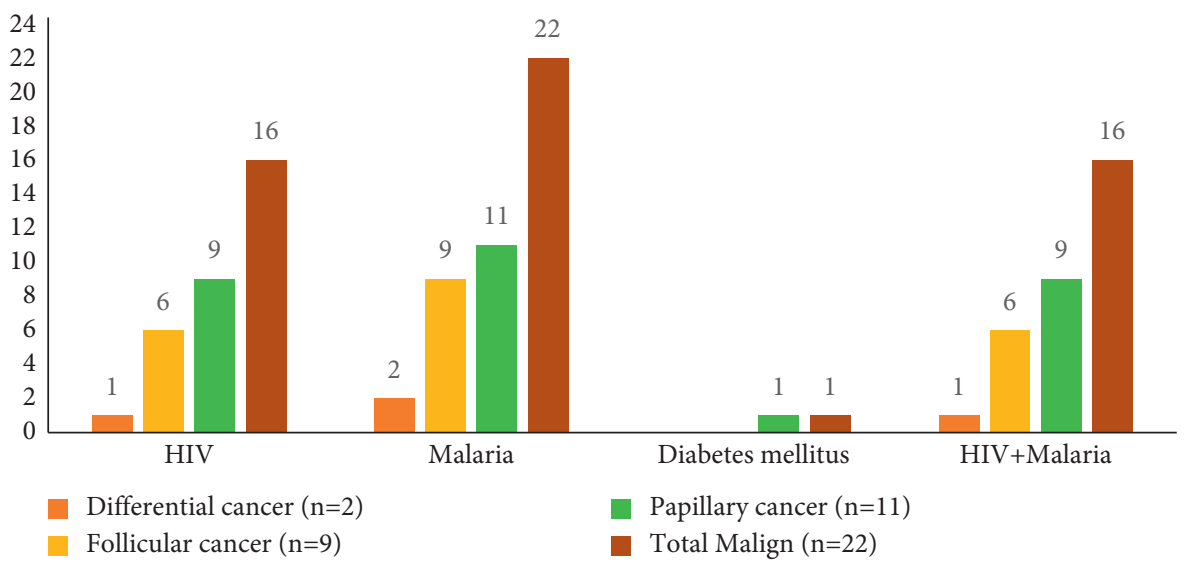

Figure 2: Distribution of thyroid cancers by comorbidities $(n=22)$, January 2017-December 2019, Somalia.

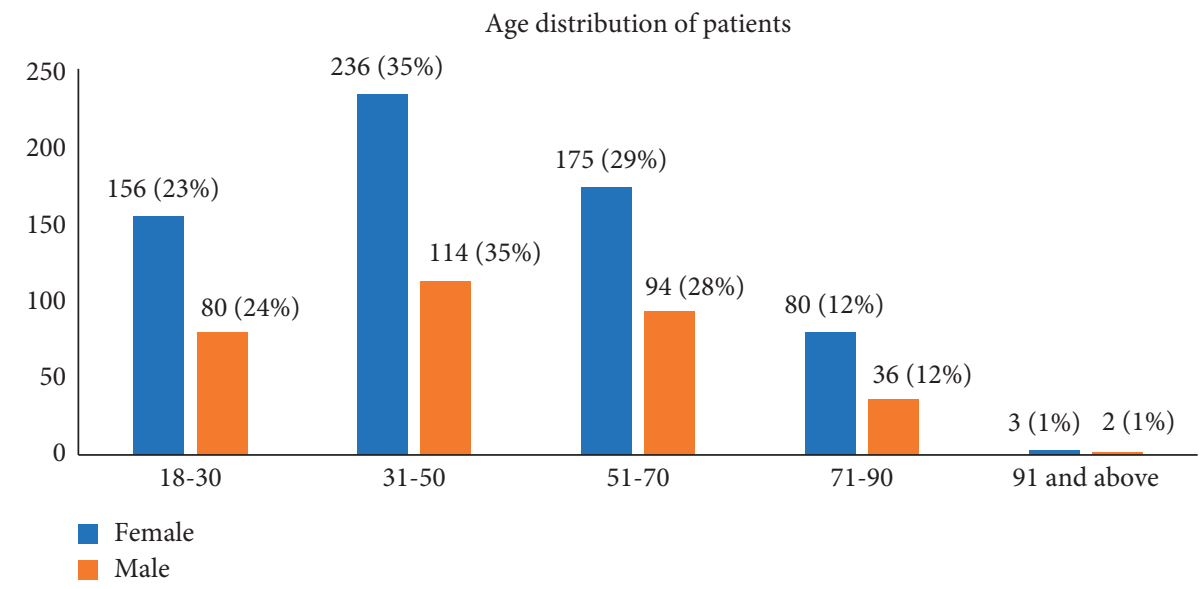

FIgURe 3: Age distribution of patients by gender $(n=976)$, January 2017-December 2019, Somalia.

28.3\% [6]. Okpara et al. reported a higher frequency of primary hypothyroidism $(4.9 \%)$ and subclinical hypothyroidism $(6.3 \%)$ [15]. This high frequency of hypothyroidism may be explained due to poor iodine nutrition, cultural beliefs, and barriers that delay the consumption or inadequate intake of these micronutrients including iodine [8]. Our study also showed that hyperthyroidism and subclinical hyperthyroidism were $7.6 \%$ and $5.7 \%$, respectively. Similarly, Okpara et al. reported a prevalence of $13.7 \%$ and $4.9 \%$ in hyperthyroidism and subclinical hyperthyroidism, and Agrawal et al. also reported 13.7\% and $3.3[6,15]$. Initiating programs such as the provision of enriching foods with iodine, prenatal $\mathrm{Fe}$, and iodine vitamin supplements, raising public awareness of the disease either through mass media (TV, radio, and social media) or through posters in healthcare centers, and providing nutrition counseling and initiating plans of action to increase health literacy in the society are necessary for the prevention of thyroid disease in the early stages.

The current study showed the association between the gender and type of thyroid disease; the euthyroid sick syndrome was common in males $(68.8 \%)$, which was similar to the study conducted by Agrawal et al. in Nepal that reported a prevalence of 73.9\% [6]. However, subclinical hyperthyroidism (6.3\%), hyperthyroidism (9.6\%), hypothyroidism (16.4\%), and subclinical hypothyroidism (13.9\%) were more common in females than in males. Although the study in Turkey reported similar hypothyroidism and subclinical hypothyroidism in females than males, subclinical hyperthyroidism and hyperthyroidism were nearly equal in both of the genders [22].

Our study showed that the age distribution in thyroid diseases was a statistically significant difference $(p \leq 0.001)$. The oldest mean age of this study was seen in euthyroid sick syndrome according to the types of thyroid disease to reason that the euthyroid sick syndrome is a common disorder in the hospitalized older people and increases with increasing age [23]. The oldest mean age of this study was seen in subclinical hypothyroidism, while the youngest mean age was seen in hyperthyroidism groups.

Diabetes mellitus is the most prevalent disorder in endocrinological diseases, while thyroid disorders were the second disease. Therefore, there is a link between thyroid dysfunction and diabetes which was documented in several studies that they are close diseases. Diabetes mellitus is associated with a higher prevalence of thyroid disease, and vice versa [24]. Studies in Nepal among thyroid comorbid DM were shown in category three after the depression and 
hypertension [25], although our study observed that $13 \%$ of thyroid patients had diabetes mellitus which was the first category before HIV and malaria.

Thyroid malignancies are the most common endocrine tumors accounting for more than $90 \%$ of endocrine tumors. Papillary thyroid cancer is the most common type of thyroid malignancy, comprising $60-65 \%$ of all thyroid cancers [26]. Follicular thyroid cancer is the second most common malignancy accounting for 15 of the cases [27]. Our study showed that papillary thyroid cancer was the most common type followed by follicular thyroid cancer, and this was similar to the UAE [28], Saudi Arabia [29], and Yemen [30], while in Sudan, the most common type of thyroid cancer was follicular thyroid cancer [31], and in Pakistan, the most type seen was papillary thyroid cancer followed by medullary carcinoma, and follicular thyroid cancer is the third most common thyroid malignancy [32].

The limitations of this study are that, first, it is a singlecentered study, while the second limitation of our study is the retrospective design with a small sample size. Larger population studies are needed in order to establish the epidemiology of thyroid disorders in our setup, but this study will be the baseline for future studies although this study is the first study of the country before and after the Civil War.

\section{Conclusion}

Thyroid disorders are one of the most common endocrine abnormalities encountered in our clinical practice. The present study demonstrated female predominance in thyroid disease, with the exception of the euthyroid sick syndrome in the male population, particularly in the elderly. The clinical profile of thyroid disease of this study comprises a wide range of disorders including hypothyroidism and subclinical hypothyroidism, hyperthyroidism and subclinical hyperthyroidism, euthyroid sick syndrome, and euthyroid. Euthyroid sick syndrome was the most common type of thyroid disease in our setup. Hypothyroidism was the second most common, followed by subclinical hypothyroidism. Papillary thyroid cancer was the predominant histology of thyroid malignancy followed by follicular thyroid cancer. Our research could be a valuable tool for decision makers in solving the burden of thyroid disease. Also, the present study sheds light on the clinical profile of thyroid disease by suggesting preventive public health strategies. Therefore, implementation of public health programs consisting of the provision of fortified food with iodine, prenatal Fe, and iodine vitamin supplements and raising public awareness of this disease through mass media may be useful in the prevention of thyroid disorders.

\section{Data Availability}

The data used to support the findings of this study are available from the corresponding author upon request.

\section{Conflicts of Interest}

The authors declare that there are no conflicts of interest regarding the publication of this paper.

\section{References}

[1] A. Thakur, "A hospital-based study for clinico-investigative profile of newly diagnosed patients of hypothyroidism," Endocrinology \& Metabolic Syndrome, vol. 08, no. 04, p. 304, 2019.

[2] A. O. Ogbera and S. F. Kuku, "Epidemiology of thyroid diseases in Africa," Indian journal of endocrinology and metabolism, vol. 15, no. Suppl2, pp. S82-S88, 2011.

[3] D. S. Mshelia, A. A. Bakari, B. M. Mubi et al., "Biochemical pattern of thyroid disorders in Maiduguri, Northeastern Nigeria," World Journal of Medicine and medical Science Research, vol. 4, no. 01, pp. 032-038, 2016.

[4] O. Sarfo-Kantanka, I. Kyei, F. S. Sarfo, and E. O. Ansah, "Thyroid disorders in Central Ghana: the influence of 20 Years of iodization," Journal of Thyroid Research, vol. 2017, Article ID 7843972, 2017.

[5] M. P. Vanderpump, "The epidemiology of thyroid disease," British Medical Bulletin, vol. 1, no. 1, p. 99, 2011.

[6] A. Agrawal, N. Rani, and R. Maskey, "Clinical profile of thyroid disorders-A retrospective study at BPKIHS," Journal of Diabetes and Endocrinology Association of Nepal, vol. 2, no. 2, pp. 19-25, 2018.

[7] A. S. Al Shahrani, A. El-Metwally, K. Al-Surimi et al., "The epidemiology of thyroid diseases in the Arab world: a systematic review," Journal of Public Health and Epidemiology, vol. 8, no. 2, pp. 17-26, 2016.

[8] "Consensus reached at the $\mathrm{FAO} / \mathrm{WHO}$ international conference on nutrition in 1992," 2021, https://extranet.who.int/ nutrition/gina/sites/default/filesstore/SOM_MN\%20Strategy \%20-\%202014-2016.pdf.

[9] C. B. Businge, B. Longo-Mbenza, and A. P. Kengne, "The prevalence of insufficient iodine intake in pregnancy in Africa: protocol for a systematic review and meta-analysis," Systematic Reviews, vol. 8, no. 1, pp. 209-217, 2019.

[10] I. A. R. Kassim, G. Moloney, A. Busili et al., "Iodine intake in Somalia is excessive and associated with the source of household drinking water," Journal of Nutrition, vol. 144, no. 3, pp. 375-381, 2014.

[11] J. R. Garber, R. H. Cobin, H. Gharib et al., "American association of clinical Endocrinologists and American thyroid association taskforce on hypothyroidism in adults. Clinical practice guidelines for hypothyroidism in adults: cosponsored by the American association of clinical Endocrinologists and the American thyroid association," Thyroid, vol. 22, no. 12, pp. 1200-1235, 2012.

[12] J. Fualal and J. Ehrenkranz, "Access, availability, and infrastructure deficiency: the current management of thyroid disease in the developing world," Reviews in Endocrine \& Metabolic Disorders, vol. 17, no. 4, pp. 583-589, 2016.

[13] Y. Suga and E. Abebe, "Patterns of surgically treated thyroid disease: a two years review at st. Paul hospital millennium medical collage, addis ababa, Ethiopia," Ethiopian Journal of Health Sciences, vol. 30, no. 1, pp. 31-36, 2020.

[14] M. A. Iddah, B. N. Macharia, A. G. Ngwena, A. Keter, and A. V. Ofulla, "Thyroid hormones and hematological indices 
levels in thyroid disorders patients at Moi teaching and referral hospital, Western Kenya," International Scholarly Research Notices, vol. 2013, Article ID 385940, 2013.

[15] H. C. Okpara, A. B. Ene, E. O. Enang, and T. M. Aluka, "Spectrum of thyroid dysfunction among patients evaluated by thyroid function tests at a tertiary clinical laboratory in Calabar, Nigeria," Annals of Medical and Health Sciences Research, vol. 7, pp. 411-417, 2017.

[16] F. O. Aram, A. A. Bahannan, and S. S. Bafakeer, "Thyroid diseases among patients from hadhramout province, Yemen," Sudan Journal of Medical Sciences, vol. 10, no. 1, pp. 15-20, 2015.

[17] E. H. Sidibé, "Thyroid diseases in sub-Saharan Africa," $\mathrm{Ca}$ hiers d'études et de recherches francophones/Santé.vol. 17, no. 1, pp. 33-39, 2007.

[18] J. Antony, T. Celine, and M. Chacko, "Spectrum of thyroid disorders: a retrospective study at a medical college hospital," Thyroid Research and Practice, vol. 11, no. 2, pp. 55-59, 2014.

[19] B. Salami, O. Odusan, H. Ebili, and P. Akintola, "Spectrum and prevalence of thyroid diseases seen at a tertiary health facility in Sagamu, South-West Nigeria," The Nigerian Postgraduate Medical Journal, vol. 23, no. 3, pp. 137-140, 2016.

[20] K. Ganesan and K. Wadud, Euthyroid Sick SyndromeIn: StatPearls. StatPearls Publishing, Treasure, Island, FL, USA, 2021, https://www.ncbi.nlm.nih.gov/books/NBK482219/.

[21] M. Suresh, N. K. Srivastava, A. K. Jain, and P. Nandy, "Thyroid dysfunction in critically ill patients in a tertiary care hospital in Sikkim, India," Thyroid Research and Practice, vol. 14, pp. 58-62, 2017.

[22] A. Sarıtaş, P. U. Sarıtaş, M. M. Kurnaz, and A. Çelik, "Spectrum and prevalence of thyroid disorders in patients admitted to the anaesthesiology outpatient clinic for surgery," Turkish journal of Anaesthesiology and Reanimation, vol. 43, no. 4, pp. 240-245, 2015.

[23] S. Tognini, F. Marchini, A. Dardano et al., "Non-thyroidal illness syndrome and short-term survival in a hospitalised older population," Age and Ageing, vol. 39, no. 1, pp. 46-50, 2010.

[24] B. Biondi, G. J. Kahaly, and R. P. Robertson, "Thyroid dysfunction and diabetes mellitus: two closely associated disorders," Endocrine Reviews, vol. 40, no. 3, pp. 789-824, 2019.

[25] P. Gupta, P. K. Agrawal, and B. Gauchan, "Prevalence of thyroid disorder in A primary care district hospital of Nepal," Journal of the Nepal Medical Association, vol. 57, no. 216, pp. 109-112, 2019.

[26] J. K. Fortson, F. L. Durden Jr, V. Patel, and A. Darkeh, "The coexistence of anaplastic and papillary carcinomas of the thyroid: a case presentation and literature review," The American Surgeon, vol. 70, no. 12, pp. 1116-1119, 2004.

[27] V. Plauche, T. Dewenter, and R. R. Walvekar, "Follicular and papillary carcinoma: a thyroid collision tumor," Indian Journal of Otolaryngology and Head \& Neck Surgery: Official Publication of the Association of Otolaryngologists of India, vol. 65, no. 1, pp. 182-184, 2013.

[28] N. Al-Zaher, S. Al-Salam, and H. El Teraifi, "Thyroid carcinoma in the United Arab Emirates: perspectives and experience of a tertiary care hospital," Hematology/Oncology and Stem Cell Therapy, vol. 1, no. 1, pp. 14-21, 2008.

[29] F. A. Qari, "Pattern of thyroid malignancy at a university hospital in western Saudi Arabia," Saudi Medical Journal, vol. 25, no. 7, pp. 866-870, 2004.

[30] Y. A. Abdulmughni, M. A. Al-Hureibi, K. A. Al-Hureibi, M. A. Ghafoor, A. H. Al-Wadan, and Y. A. Al-Hureibi,
“Thyroid cancer in Yemen," Saudi Medical Journal, vol. 25, pp. 55-59, 2004.

[31] M. Omran and M. E. Ahmed, "Carcinoma of the thyroid in khartoum," East African Medical Journal, vol. 70, pp. 159-162, 1993.

[32] S. Altaf, Z. Mehmood, M. N. Baloch, and A. Javed, "Experience of thyroid surgery at a tertiary care hospital in Karachi, Pakistan," Open Journal of Thyroid Research, vol. 2, no. 1, pp. 009-014, 2019. 